\title{
Deformation Behavior of 6061 Aluminum Alloy Through Tube Channel Pressing: Severe Plastic Deformation
}

\author{
M.H. Farshidi and M. Kazeminezhad
}

(Submitted November 3, 2011; in revised form December 24, 2011)

\begin{abstract}
The deformation behavior of solid solution-treated AA6061 tubes in a novel severe plastic deformation process named Tube Channel Pressing has been assessed. In order to do so, an analysis based on the finite element method and dislocation density model is utilized, and microhardness measurement is carried out to verify the trends of analysis results. By comparing FEM results with experimental data, the optimized geometrical parameters controlling the deformation behavior of the tube in tube channel pressing are determined to obtain the best strain homogeneity and minimum dimensional changes in tube.
\end{abstract}

Keywords AA6061, deformation behavior, severe plastic deformation, tube channel pressing

\section{Introduction}

Severe plastic deformation (SPD) processes can be classified as a method to produce nano-structured and ultrafine grained materials. Many of these processes have been introduced in past few decades to impose large plastic strains on several shapes of materials. For example, Equal Channel Angular Pressing (ECAP) (Ref 1-4) has been developed for rods, High Pressure Torsion (HPT) (Ref 5-7) has been focused on disks, and Accumulative Roll Bonding (ARB) (Ref 8-11) and Constrained Groove Pressing (CGP) (Ref 12-14) have been developed for sheets.

Although many SPD processes have been innovated recently (Ref 15-17), SPD of tubes had been less considered. One introduced process for SPD of tube is the High Pressure Torsion of Tubes (HPTT) which was presented by Toth et al. (Ref 18). In this process, the tube is placed between a rigid disk and axially pressed mandrel. Afterward, rigid disk starts to rotate, and this causes to shear deformation on fixed tube. Although large amounts of plastic strains can be achieved from this process, some disadvantages confine its application as a common SPD process for tubes. First of all, pressure as high as $10^{9} \mathrm{MPa}$ is required for this process which limits the dimensions of specimen. Second, the amount of plastic strain varies linearly along with thickness of tube wall. Finally, production of SPD-ed specimen needs complicated and expensive machine.

Concerning what mentioned above, a new SPD process for tubes has been recently developed by Zangiabadi and Kazeminezhad (Ref 19) called Tube Channel Pressing (TCP). TCP process has been successfully used for SPD of commercially pure aluminum up to equivalent plastic strain of 5 , and it has

M.H. Farshidi and M. Kazeminezhad, Department of Materials Science and Engineering, Sharif University of Technology, Azadi Avenue, Tehran, Iran. Contact e-mail: mkazemi@sharif.edu. been reported that the achievements of grain refinement and strength improvement are considerable in this process. Since TCP is a new process, the effects of geometrical parameters controlling deformation in this process have not yet been investigated. Therefore, in this study, the effects of main geometrical parameters in TCP of solid solution treated AA6061 tube have been assessed on the basis of an analysis considering the finite element method and dislocation model.

\section{Tube Channel Pressing (TCP) and Procedure}

As shown in Fig. 1, TCP process is based on pressing the tube between a die and mandrel, which causes consecutive reducing and increasing of inner and outer diameter of tube. In this process, surface of mandrel includes a cave and surface of die includes a convex, both of which consist of three tangent circles as shown in Fig. 2. Based on this curvature, geometric parameters of die and mandrel shown in Fig. 2 can be related as follows:

$\Delta r_{\text {die }}=2 R_{\text {die }}\left(1-\cos \theta_{\text {die }}\right)$

$H_{\text {die }}=2 R_{\text {die }} \sin \theta_{\text {die }}$

$\Delta r_{\text {mandrel }}=2 R_{\text {mandrel }}\left(1-\cos \theta_{\text {mandrel }}\right)$

$H_{\text {mandrel }}=2 R_{\text {mandrel }} \sin \theta_{\text {mandrel }}$

where $R_{\text {mandrel }}$ and $R_{\text {die }}$ are the radii of mandrel and die curvatures, respectively; $\theta_{\text {mandrel }}$ and $\theta_{\text {die }}$ are, respectively, the contact angles of mandrel and die; $\Delta r_{\text {mandrel }}$ and $\Delta r_{\text {die }}$ are, respectively, the depth of mandrel cave and hill of die convex; and $H_{\text {mandrel }}$ and $H_{\text {die }}$ are, respectively, the lengths of mandrel cave region and die convex region, respectively.

Concerning these relations, two independent geometrical parameters can be defined to represent curvature of cave in mandrel. In order to investigate the mandrel design, these two independent parameters can be defined as $R_{\text {mandrel }}$ and $\Delta r_{\text {mandrel }}$.

Although the TCP process can be defined by two independent parameters for either die or mandrel, one can guess that curvatures of die and mandrel cannot be independent of each 
other completely. This means that if mandrel and die are designed fully independent, TCP process may have problem during experimental processing. For example, if cross-sectional area of bottleneck region between die convex and mandrel cave is more or less than initial tube cross section area, TCP process may be accompanied by severe thickening or extruding in the neck region. This may result to increase in equivalent plastic strain and may cause fracture during process.

In the next sections, the effects of two independent geometrical parameters for mandrel design of TCP process will be studied. First, the effects of $\Delta r_{\text {mandrel }}$ will be investigated by mathematical simulations for three different $\Delta r_{\text {mandrel }}$ values, while other parameters are constant. Next, the effect of $R_{\text {mandrel }}$ as an important mandrel design parameter will be

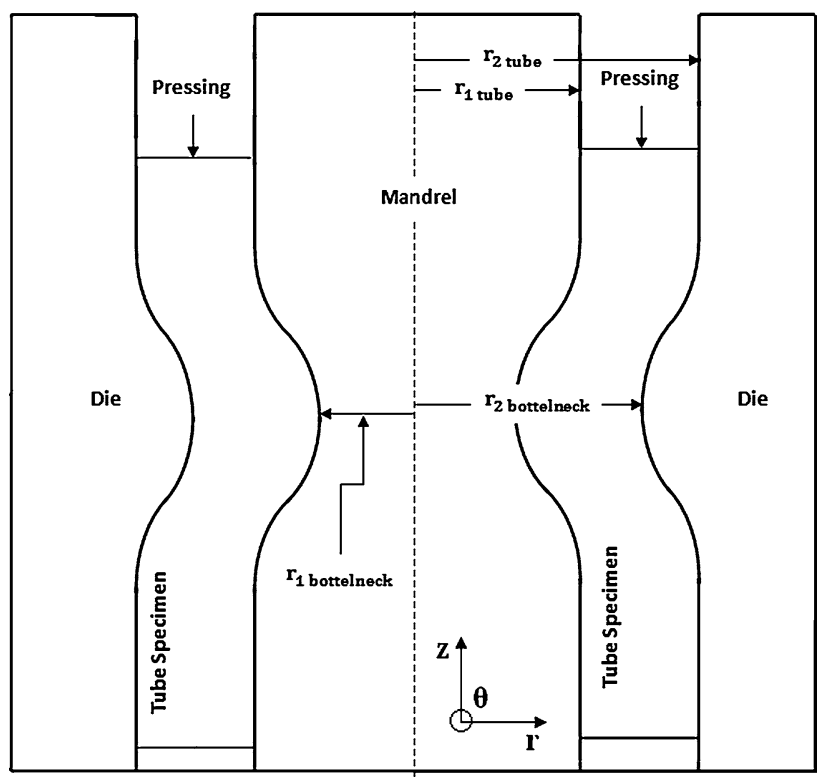

Fig. 1 Basis of TCP process

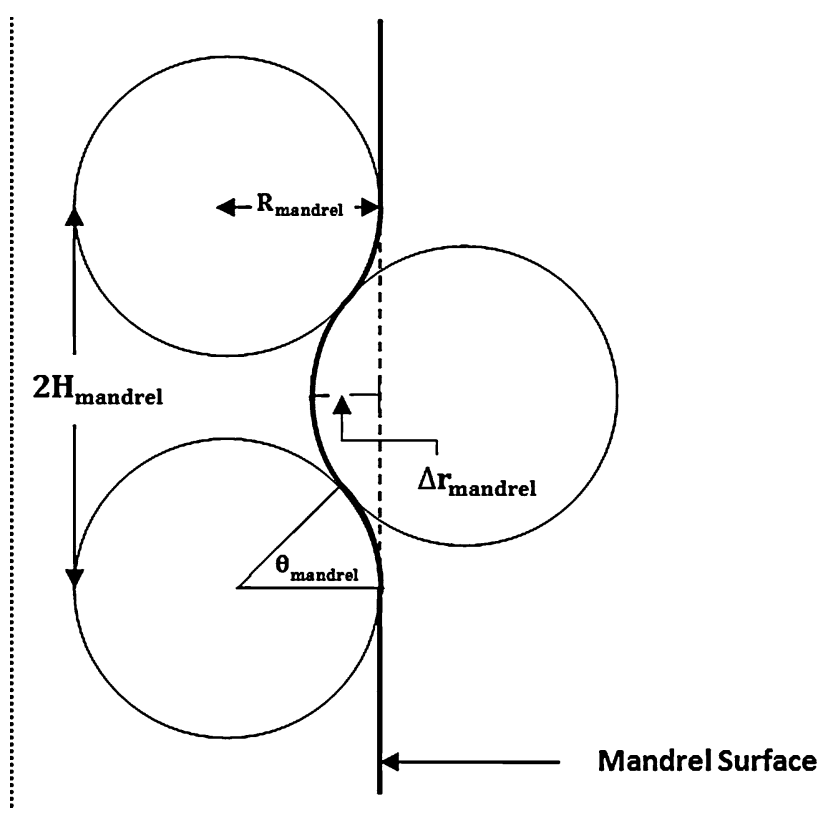

Fig. 2 Geometrical parameters of mandrel subjected. For this purpose, three different $R_{\text {mandrel }}$ can be considered. Finally, the results of simulations will be compared with the results achieved experimentally.

\section{Mathematical Simulation of TCP Process}

In order to assess the effect of TCP process on AA6061, a mathematical simulation based on dislocation model and FEM method was utilized through ABAQUS/CAE 6.9 software.

For determining the effect of $\Delta r_{\text {mandrel }}$, three different amounts were admitted for $\Delta r_{\text {mandrel }}$; in one of these, tube cross section was maintained constant during TCP. In this regard, considering $r_{1}$ tube and $r_{2}$ tube, as inner and outer diameters of tube, and, $r_{1}$ bottelneck and $r_{2}$ bottelneck as inner and outer diameters of bottleneck region between die and mandrel (see Fig. 1), it can be written that

$r_{2 \text { tube }}^{2}-r_{1 \text { tube }}^{2}=r_{2 \text { bottelneck }}^{2}-r_{1 \text { bottelneck }}^{2}$

Thus, inner diameter of bottleneck region is dependent on inner and outer diameters of tube and outer diameter of bottleneck. Regarding the relations

$\Delta r_{\text {mandrel }}=r_{1 \text { tube }}-r_{1 \text { bottelneck }}$

$\Delta r_{\text {die }}=r_{2 \text { tube }}-r_{2 \text { bottelneck }}$

One amount for $\Delta r_{\text {mandrel }}$ can be defined wherein the cross section of tube between die and mandrel in bottleneck region is equal to the initial cross section of tube. This amount named $\Delta r_{\text {mandrel}}^{*}$, will satisfy Eq 5 . Two other amounts for $\Delta r_{\text {mandrel }}$ were selected-smaller and greater than $\Delta r_{\text {mandrel }}^{*}$. In these designs, $R_{\text {mandrel }}$ was considered as $7.5 \mathrm{~mm}$, and inner and outer diameters of tube were 19 and $26 \mathrm{~mm}$. Die was designed with a contact angle of $25.8^{\circ}$ and radius of $7.5 \mathrm{~mm}$. This leads

Table 1 Geometrical parameters for different mandrels designed for TCP process

\begin{tabular}{lcccl}
\hline Process & $\boldsymbol{\theta}_{\text {mandrel }}{ }^{\circ}$ & $\begin{array}{c}\boldsymbol{R}_{\text {mandrel}}, \\
\mathbf{m m}\end{array}$ & $\begin{array}{c}\boldsymbol{\Delta} \boldsymbol{r}_{\text {mandrel }}, \\
\mathbf{m m}\end{array}$ & $\begin{array}{c}\boldsymbol{H}_{\text {mandrel }} \\
\mathbf{m m}\end{array}$ \\
\hline Mandrel 1 & 25.8 & 7.5 & 1.5 & 6.53 \\
Mandrel 2 & 31.4 & 7.5 & 2.2 & 7.81 \\
Mandrel 3 & 36.9 & 7.5 & 3 & 9 \\
Mandrel 4 & 38.7 & 5 & 2.2 & 6.25 \\
Mandrel 5 & 27.1 & 10 & 2.2 & 9.11 \\
\hline
\end{tabular}

Table 2 Calculated constant in adapting Eq 12 with experimental result of AA6061 solid solution-treated alloy

\begin{tabular}{lccc}
\hline Parameter & $\boldsymbol{\sigma}_{\mathbf{1}}, \mathbf{M P a}$ & $\boldsymbol{c}_{\mathbf{1}}, \mathbf{M P a}$ & $\boldsymbol{c}_{\mathbf{2}}$ \\
\hline Magnitude & 501 & 420 & 2.74 \\
\hline
\end{tabular}

Table 3 Chemical composition of AA6061 tube used for experiments

\begin{tabular}{ccccccccc}
\hline Al & Mg & Si & Cu & Fe & Cr & Zn & Mn & V \\
\hline Base & 1.01 & 0.486 & 0.312 & 0.241 & 0.0551 & 0.0484 & 0.0104 & 0.0142
\end{tabular}


to $\Delta r_{\text {die }}$ and $H_{\text {die }}$ of 1.5 and $6.53 \mathrm{~mm}$, respectively. It is notable that die and mandrel were designed with clearances of 0.15 and $0.1 \mathrm{~mm}$ from tube surface, respectively, to decrease the effects of friction and tool wearing.

In order to investigate the effect of $R_{\text {mandrel }}$ on TCP process, designs with three different values of $R_{\text {mandrel }}$ were compared. In these designs, $R_{\text {mandrel }}$ were regarded as $5,7.5$, and $10 \mathrm{~mm}$ which are smaller, equal, and more than $R_{\text {die }}$, respectively, while $\Delta r_{\text {mandrel }}$ is constant and equal to $\Delta r_{\text {mandrel }}^{*}$. This leads to $\theta_{\text {mandrel }}$ to be $39^{\circ}, 31.4^{\circ}$, and $27^{\circ}$, respectively. Table 1 shows all geometric parameters of mandrels mentioned above.

FEM simulation was based on Langrangian formulation, and the applied approach was Dynamic Explicit. All parts such as tube, die, and mandrels were considered as axisymmetric,

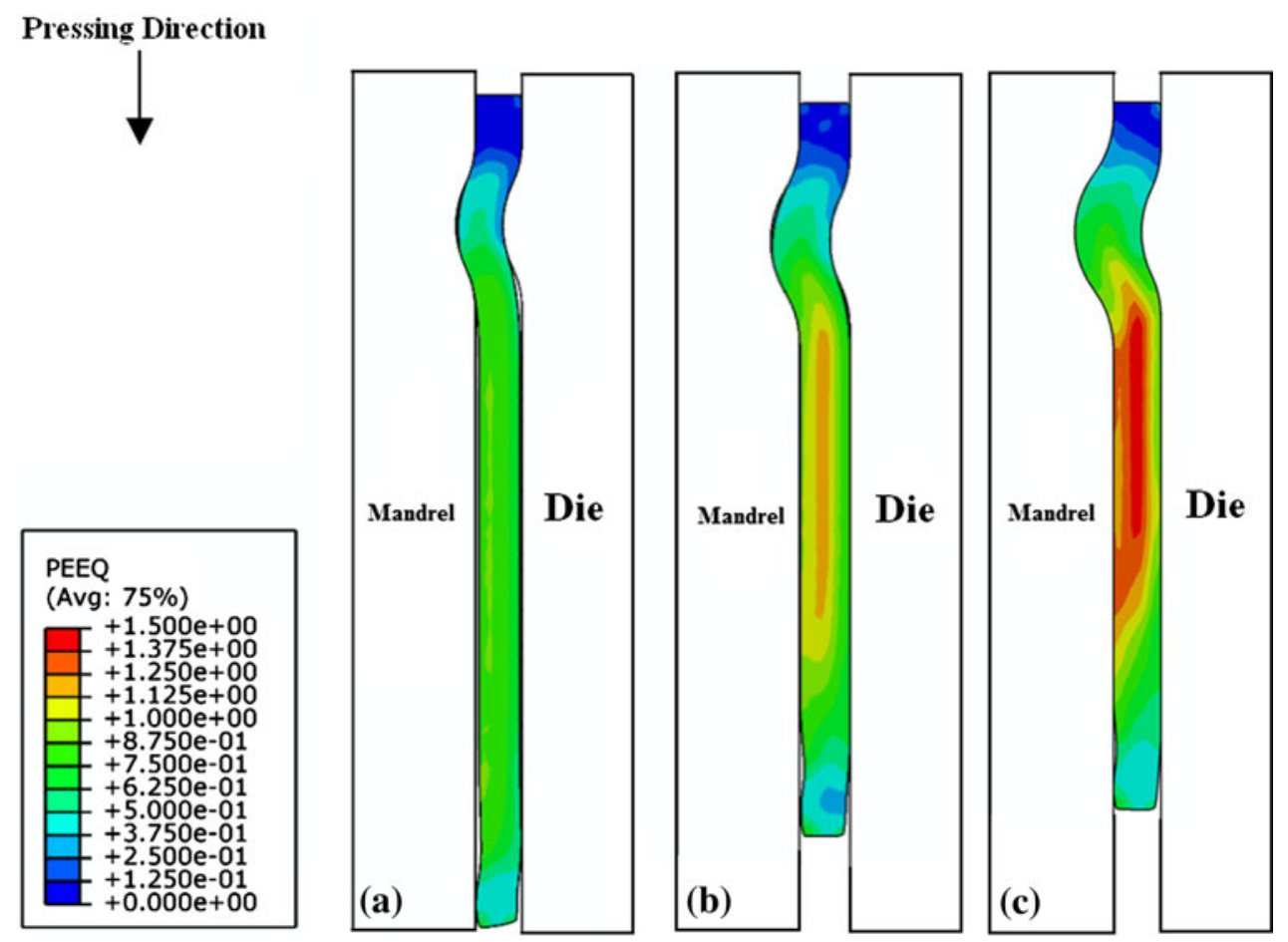

Fig. 3 Distribution of equivalent strain in tube when processed by mandrel with cave depth of (a) 1.5, (b) 2.2, and (c) $3 \mathrm{~mm}$

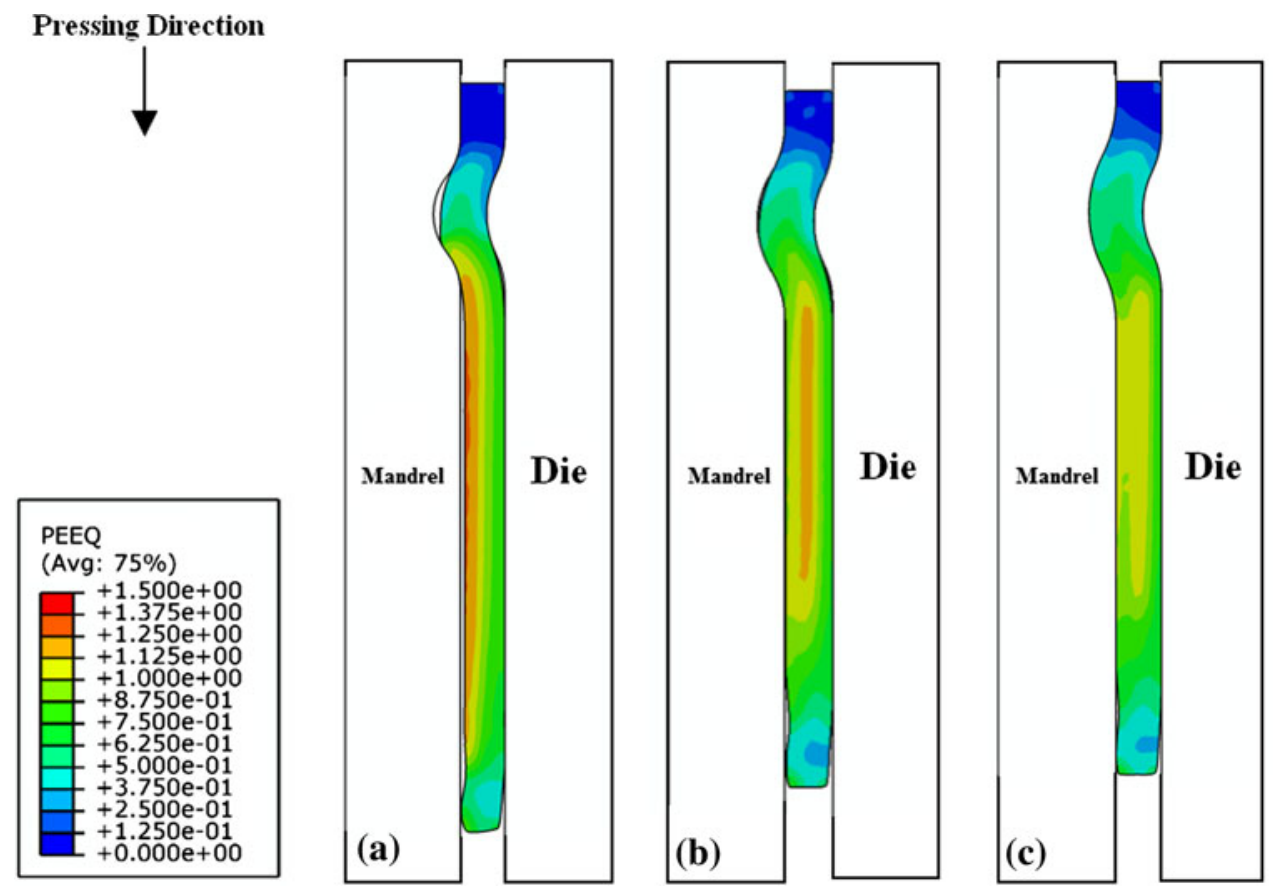

Fig. 4 Distribution of equivalent strain in tube when processed by mandrel with curvature radius of (a) 5, (b) 7.5 , and (c) $10 \mathrm{~mm}$ 
two-dimensional. Tube was considered as deformable, while die and mandrel were discrete rigid. Die and mandrel surfaces were meshed by 68 and 72 number of RAX2 elements, respectively, which are linear elements with one node on each side. Both sides of bottleneck region contained 40 elements. Thus, element size of bottleneck region was of the order of $0.4 \mathrm{~mm}$. Element size in other regions of die and mandrel was of the order of $14 \mathrm{~mm}$ because these regions do not have any role in deformation. Tube was meshed by 840 CAX4R elements which are rectangles with one node on each corner and dimensions of elements were $0.5 \times 0.5 \mathrm{~mm}$. For investigating the mesh sensitivity of simulation, one simulation was achieved using elements with half size of the mentioned amounts, and no significant change in results was observed.

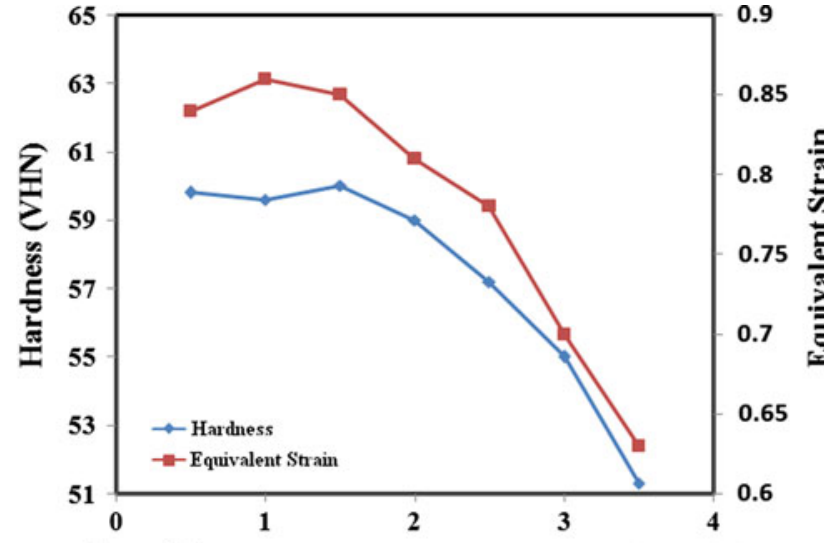

(a)
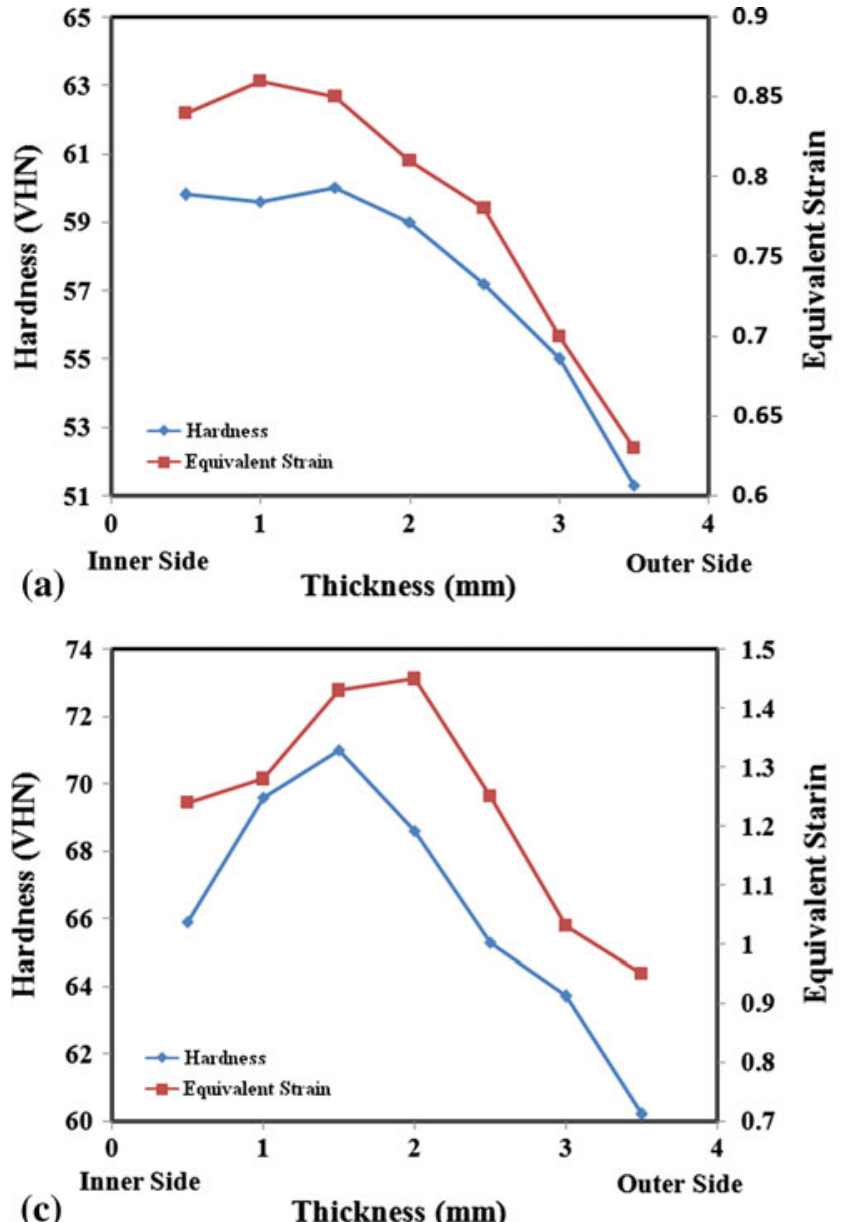

(c)

Thickness (mm)

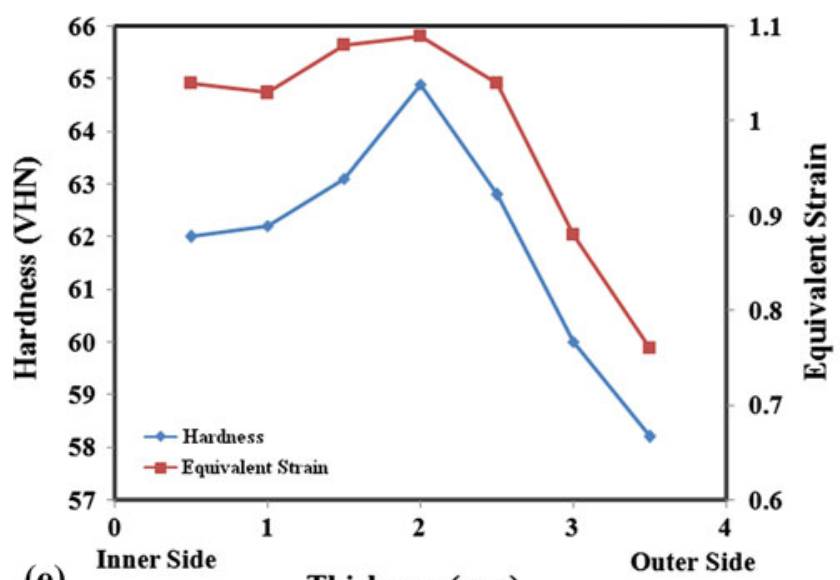

(e)

Inner Side

Thickness (mm)

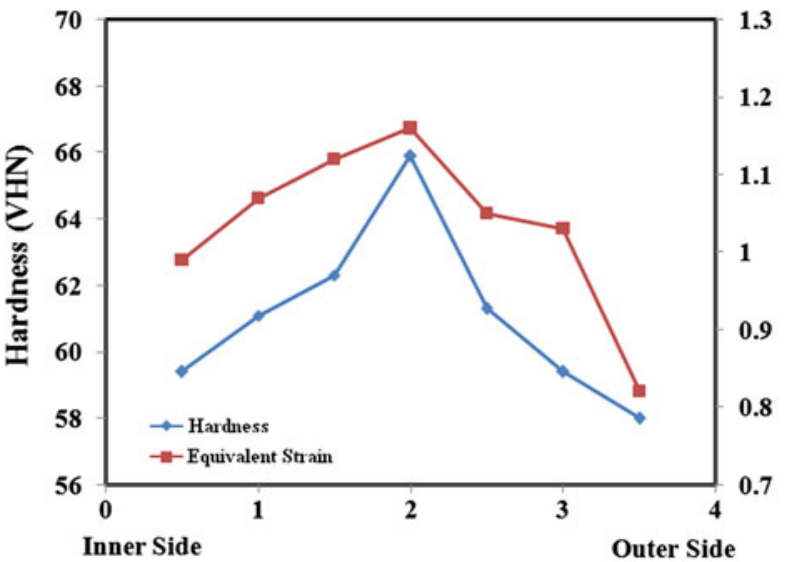

(b)

Thickness (mm)

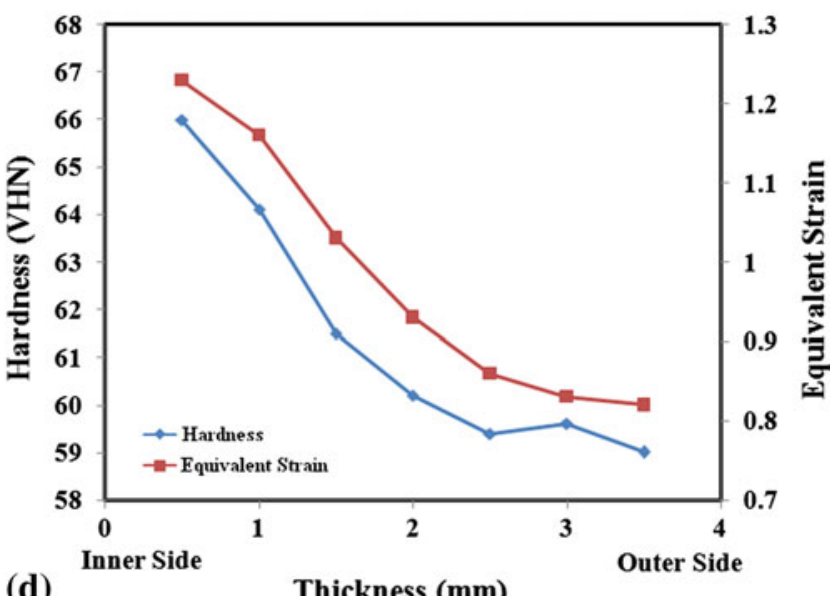

(d)

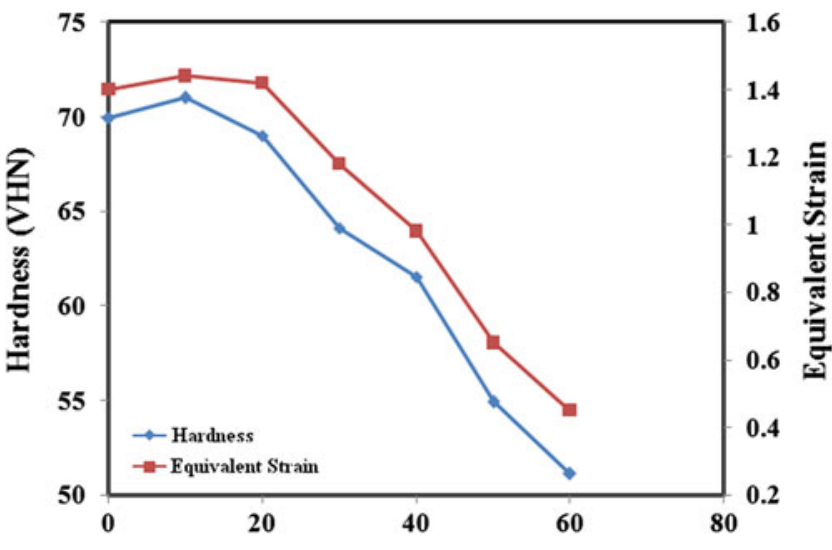

(f)

$\mathbf{L}(\mathbf{m m})$

Fig. 5 Comparison of equivalent strain and Vickers microhardness in tube thickness when $R_{\text {mandrel }}$ and $\Delta r_{\text {mandrel }}$ are, respectively, of (a) 7.5 and 1.5, (b) 7.5 and 2.2, (c) 7.5 and 3, (d) 5 and 2.2, (e) 10 and 2.2. (f) Comparison of Vickers microhardness with equivalent strain along length direction for specimen processed by mandrel mentioned in (c). L: length after bottleneck region 
In order to find stress-strain curve of AA6061 solid solutiontreated aluminum alloy in large strains, a dislocation density based model was used. Considering differential equation (Ref 20)

$\frac{d \rho}{k_{1} \sqrt{\rho}-k_{2} \rho}=d \varepsilon$

where $\rho$ is the dislocation density, $\varepsilon$ is the equivalent strain, and $k_{1}$ and $k_{2}$ are the material constants, it leads to

$\varepsilon=\varepsilon_{0}-\frac{2}{k_{2}} \ln \left(k_{1}-k_{2} \sqrt{\rho}\right)$

where $\varepsilon_{0}$ is the boundary condition constant for strain. On the other hand, flow stress can be written as (Ref 21)
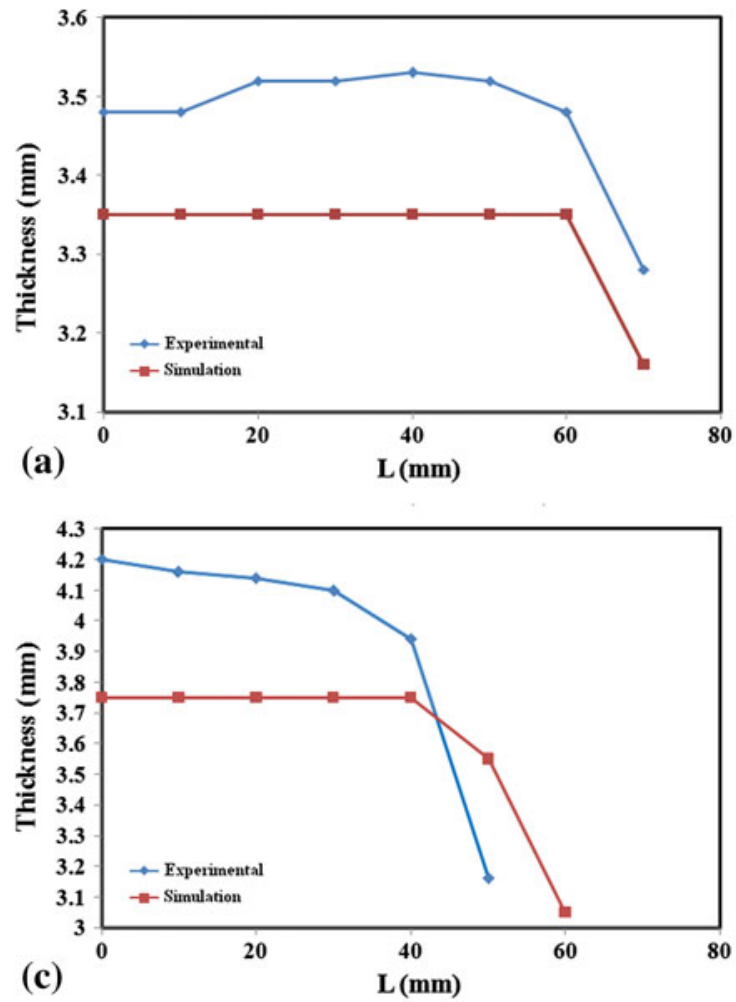

$\sigma=\sigma_{0}+\alpha G b \sqrt{\rho}$

where $\sigma_{0}$ and $\alpha$ are the material constants, $G$ is the shear module, and $b$ is the burgers vector. Combining Eq 9 and 10, we have

$\sigma=\sigma_{0}+\alpha G b\left(\frac{k_{1}}{k_{2}}\right)-\frac{\alpha G b}{k_{2}} \exp \left(-\frac{k_{2}\left(\varepsilon-\varepsilon_{0}\right)}{2}\right)$

This equation can be rewritten as

$\sigma=\sigma_{1}-c_{1} \exp \left(-c_{2} \varepsilon\right)$

where $\sigma_{1}, c_{1}, c_{2} \geq 0$
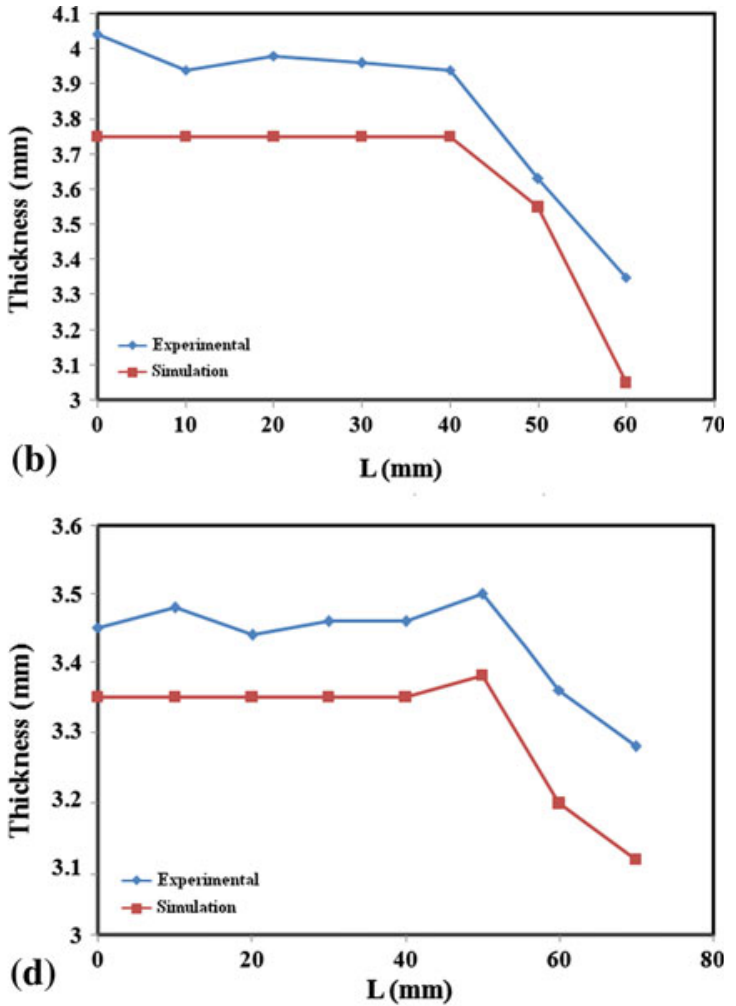

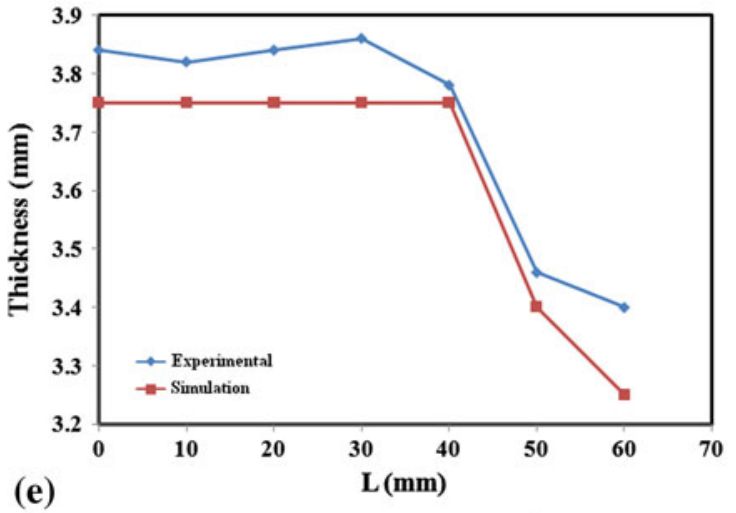

Fig. 6 Variation of tube thickness with tube length when processed by mandrel with $R_{\text {mandrel }}$ and $\Delta r_{\text {mandrel }}$ values are, respectively, of (a) 7.5 and 1.5 , (b) 7.5 and 2.2 , (c) 7.5 and 3, (d) 5 and 2.2, (e) 10 and 2.2. L: length after bottleneck region 
These constants can be calculated by adapting Eq 12 with stress-strain curve of solid solution-treated AA6061 alloy. The calculated constants have been shown in Table 2 .

\section{Experimental Procedure}

Chemical analysis of the studied AA6061 tube has been presented in Table 3.75-mm-length pieces of tubes were solution treated in $530{ }^{\circ} \mathrm{C}$ for $1 \mathrm{~h}$ and quenched in water. Specimens were deformed in one pass of TCP process using the different mandrel designs. $\mathrm{MoS}_{2}$ lubricant was used to decrease the effect of friction. After TCP, specimens were held in frozen mixture of water and $10 \mathrm{wt} . \%$ ethylene glycol to prevent natural aging.

Vickers microhardness measurements were carried out through $r$-direction in $z-r$ plane (see Fig. 1) on thickness of tubes with a load of $200 \mathrm{~g}$. For this purpose, after TCP process, tubes were cut into two halves through longitudinal direction and then one half was polished and prepared for microhardness measurement. Tensile test specimens were machined in longitudinal direction of tube with gauge length of $32 \mathrm{~mm}$ in accordance to ASTM E8M, and tensile tests were accomplished in strain rate of $5 \times 10^{-4} \mathrm{~s}^{-1}$.

\section{Results and Discussion}

Distributions of calculated equivalent plastic strain for designed mandrels with different cave depths have been shown in Fig. 3. Average equivalent strains are $0.78,1.03$, and 1.23 in steady-state region where $\Delta r_{\text {mandrel }}$ values are $1.5,2.2$, and $3 \mathrm{~mm}$, respectively. As shown here, total amount of strain accumulated in tube wall increases with increasing $\Delta r_{\text {mandrel. }}$. However, equivalent strain is not homogenously distributed in tube wall. The inhomogenity factor (IF) is defined as

$\mathrm{IF}=\frac{\varepsilon_{\mathrm{max}}-\varepsilon_{\min }}{\varepsilon_{\text {average }}}$

where $\varepsilon_{\max }, \varepsilon_{\min }$, and $\varepsilon_{\text {average }}$ are the maximum, minimum, and average strains in the wall of TCP-ed tube. IFs were $0.17,0.33$, and 0.41 for specimens processed by mandrels with cave depths of $1.5,2.2$, and $3 \mathrm{~mm}$, respectively. Therefore, it can be inferred that inhomogeneity of equivalent strain decreases with decreasing cave depth of mandrel.

On the other hand, although mandrel with minimum cave depth had the best homogeneity of equivalent strain, tube wall thinning after passing the tube from neck region was obvious in processing with this mandrel and caused to lengthening of tube. This phenomenon is in conflict with SPD fundamentals. Thus, mandrel's cross-sectional design must be kept balanced between thinning and plastic strain homogeneity.

Differences in equivalent strain can be traced in longitudinal direction of tube, and unsteady-state region appears during initial step of TCP process. This unsteady-state region has a lower equivalent strain and curved shape. Tracing equivalent strain in the middle of tube wall thickness along length in Fig. 3 shows that unsteady-state region is large in specimen processed with mandrel which has a maximum cave depth. This may make it an undesirable mandrel for TCP.

Figure 4 compares distributions of equivalent strain for mandrel designs which have the same cave depth of $2.2 \mathrm{~mm}$ but with different curvature radii. Average equivalent strains are $0.98,1.03$, and 0.99 for specimens processed with 5-, 7.5-, and $10-\mathrm{mm}$ curvature radii, respectively. As can be inferred, average equivalent strains are almost constant for all the mentioned mandrels. On the other hand, IFs are $0.42,0.33$, and 0.28 for specimens processed with $5,7.5$ and $10 \mathrm{~mm}$ curvature radii, respectively. This means that homogeneity of equivalent strain increases with increasing the mandrel curvature radius, $R_{\text {mandrel }}$. Unsteady-state region is constricted in specimen processed by 5-mm curvature radius of mandrel comparing with those of two other ones, also. Nevertheless, as shown in Fig. 4, this mandrel design causes thinning in tube wall after passing the tube from neck region, which makes it unsuitable for SPD. This dictates that mandrel radius must be greater than or equal to die radius to avoid from thinning of tube wall.

Figure 5(a)-(e) compares hardness profile with simulation results for equivalent strain through thickness direction of TCPed tubes by all mandrel designs. As shown here, the trends of strain and hardness variations are consistent which verifies simulation results. On the other hand, variation of strain along length direction and existence of unsteady-state region are in agreement with hardness evaluations. For example, Fig. 5(f) compares changes in hardness and equivalent strain through tube length for specimen processed with 3-mm cave depth mandrel which demonstrates initial unsteady-state region with lower hardness consistent with predicted strain in simulation.
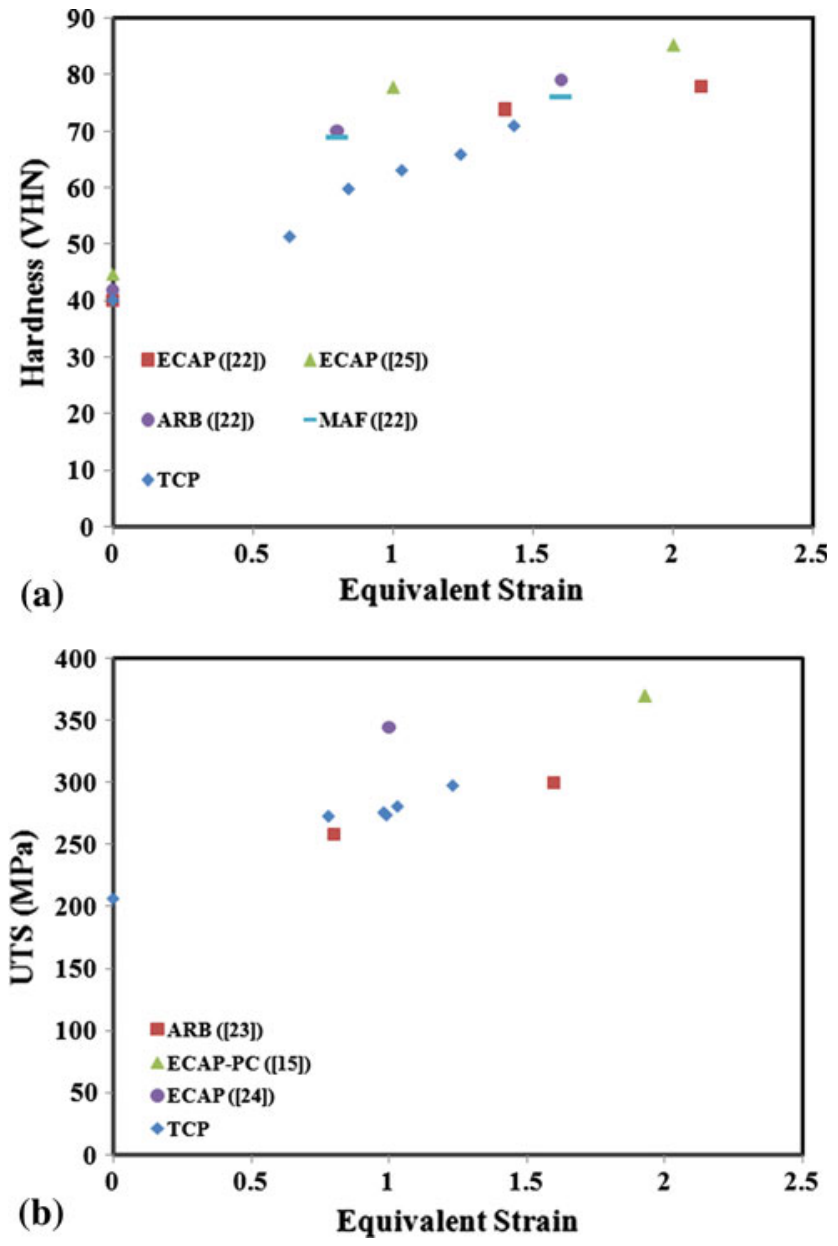

Fig. 7 Comparison of (a) Vickers microhardness and (b) UTS of aluminum AA6061 alloy after TCP with those after SPD processes 
Figure 6 compares simulation results with experimental results for thickness variation through length. As shown here, experimental results for tube thickness are in agreement with simulation results. Distinctively, as shown in Fig. 6(a) and (d), the experiments show thinning of tube in two mandrel designs during process which had been predicted by simulation. Also, curved shape regions in initial unsteady-state regions of all the specimens are observed as predicted by simulation.

Figure 7 compares variations of microhardness and ultimate tensile stress (UTS) versus equivalent strain in TCP with those in other SPD processes (Ref 15, 22-25). As shown here, TCP is a process can help in increasing mechanical properties of tube and yields the same Vickers micro-hardness and UTS compared with those in other SPD processes, such as ECAP, ARB, and Multi Axial Forging (MAF).

\section{Conclusions}

The effect of mandrel design on TCP process of AA6061 was studied. Investigations were carried out based on an analysis and experiments. Cave depth and curvature radius of mandrel were regarded as geometrical independent parameters of mandrel design. Main results can be listed as follows:

(1) Increasing the cave depth amount increases equivalent strain and spread of unsteady-state region in initial step of TCP process. It also decreases the homogeneity of equivalent strain through tube wall thickness.

(2) Decreasing the cave depth amount to lower than $\Delta r_{\text {mandrel }}^{*}$, leads to thinning in tube wall thickness during TCP. Thus, mandrel cave depth must be equal to $\Delta r_{\text {mandrel }}^{*}$ to avoid wall thinning and exceed that of equivalent strain homogeneity.

(3) Decreasing the curvature radius of mandrel limits the unsteady-state region, while the strain inhomogeneity increases. On the other hand, choosing $R_{\text {mandrel }}$ less than $R_{\text {die }}$ leads to tube wall thinning. Thus, $R_{\text {mandrel }}$ must be more than $R_{\text {die }}$.

(4) The results of analysis are in agreement with the experimental data.

\section{Acknowledgments}

The authors wish to thank the Iran National Science Foundation (INSF), and the research board of Sharif University of Technology for the financial support and the provision of the research facilities used in this study.

\section{References}

1. V.M. Segal, USSR Patent No. 575892, 1977

2. V.M. Segal, Severe Plastic Deformation: Simple Shear Versus Pure Shear, Mater. Sci. Eng. A, 2003, 338, p 331-344

3. Y. Iwahashi, J. Wang, Z. Horita, M. Nemoto, and T.G. Langdon, Principle of Equal-Channel Angular Pressing for the Processing of Ultra-Fine Grained Materials, Scripta Mater., 1996, 35, p 143-146
4. C. $\mathrm{Xu}, \mathrm{Z}$. Horita, M. Furukawa, and T.G. Langdon, Using Equal Channel Angular Pressing for the Production of Super Plastic Aluminum and Magnesium Alloy, J. Mater. Eng. Perform., 2004, 13, p 683-690

5. R.Z. Valiev, N.A. Krasilnikov, and N.K. Tsene, Plastic Deformation of Alloys with Submicron-Grained Structure, Mater. Sci. Eng. A, 1991, 35, p 135-137

6. R.Z. Valiev, Structure and Mechanical Properties of Ultrafine-Grained Metals, J. Mater. Sci. Eng., 1997, 59, p 234-235

7. O.N. Senkov, F.H. Froes, V.V. Stolyarov, R.Z. Valiev, and J. Liu, Microstructure of Aluminum-Iron Alloy Subjected to Plastic Deformation, Scripta Mater, 1998, 38, p 1151-1156

8. R. Jamaati, S. Amirkhanlou, M.R. Toroghinejad, and B. Niroumand, Comparison of the Microstructure and Mechanical Properties of As-Cast A356/SiC MMC Processed by ARB and CAR Methods, J. Mater. Eng. Perform., 2011. doi:10.1007/s11665-011-0045-7

9. N. Tsuji, Y. Saito, H. Utsunomiya, and S. Tanigawa, Ultra-Fine Grained Bulk Steel Produced by Accumulative Roll-Bonding (ARB) Process, Scripta Mater., 1999, 40, p 795-800

10. V.L. Niranjani, K.C. Hari Kumar, and V. Subramanya Sarma, Development of High Strength Al-Mg-Si AA6061 Alloy Through Cold Rolling and Ageing, Mater. Sci. Eng. A, 2009, 515, p 169-174

11. N. Tsuji, T. Toyoda, Y. Minamino, Y. Koizumi, T. Yamane, M. Komatsu, and M. Kiritani, Microstructural Change of UltrafineGrained Aluminum During High Speed Plastic Deformation, Mater. Sci. Eng. A, 2003, 350, p 108-116

12. Y.T. Zhu, T.C. Lowe, H. Jiang, and J. Huang, U.S. Patent No. 6197129 B1, 2001

13. J.Y. Huang, Y.T. Zhu, H. Jiang, and T.C. Lowe, Microstructure and Dislocation Configuration in Nanostructured $\mathrm{Cu}$ Processed by Repetitive Corrugation and Straightening, Acta Mater, 2001, 49, p 14971505

14. S.C. Yoon, A. Krishnaiah, U. Chakkingal, and H.S. Kim, Severe Plastic Deformation and Strain Localization in Groove Pressing, Comp. Mater. Sci., 2008, 43, p 641-645

15. M.Y. Murashkin, E.V. Bobruk, A.R. Kil'mametov, and R.Z. Valiev, Structure and Mechanical Properties of Aluminum Alloy 6061 Subjected to Equal-Channel Angular Pressing in Parallel Channels, Phys. Met. Metalog., 2009, 108, p 415-423

16. M.R. Shankar, S. Chandrasekar, A.H. King, and W.D. Compton, Microstructure and Stability of Nanocrystalline Aluminum 6061 Created by Large Strain Machining, Acta Mater., 2005, 53, p 47814793

17. A.V. Nagasekhar and H.S. Kim, Plastic Deformation Characteristics of Cross-Equal Channel Angular Pressing, Comp. Mater. Sci., 2008, 43, p 1069-1073

18. L.S. Toth, M. Arzaghi, J.J. Fundenberger, B. Beausir, O. Bouaziz, and R. Arruffat-Massion, Severe Plastic Deformation of Metals by HighPressure Tube Twisting, Scripta Mater, 2009, 60, p 175-177

19. A. Zangiabadi and M. Kazeminezhad, Development of a Novel Severe Plastic Deformation Method for Tubular Materials: Tube Channel Pressing (TCP), Mater. Sci. Eng. A, 2011, 528, p 5066-5072

20. Y. Estrin and H. Mecking, An Extension of the Bonder-Partom Model of Plastic Deformation, Int. J. Plast., 1987, 2, p 73-85

21. G.E. Dieter, Mechanical Metallurgy, 4th ed., McGraw Hill, New York, 1986, p 191

22. B. Cherukuri, T.S. Nedkova, and R. Srinivasan, A Comparison of the Properties of SPD-Processed AA-6061 by Equal-Channel Angular Pressing, Multi-Axial Compressions/Forgings and Accumulative Roll Bonding, Mater. Sci. Eng. A, 2005, 410-411, p 394-397

23. M.R. Rezaei, M.R. Toroghinejad, and F. Ashrafizadeh, Effects of ARB and Ageing Processes on Mechanical Properties and Microstructure of 6061 Aluminum Alloy, J. Mater. Process. Technol., 2011, 211, p 1184 1190

24. W.J. Kim and J.Y. Wang, Microstructure of the Post-ECAP Aging Processed 6061 Al Alloys, Mater. Sci. Eng. A, 2007, 464, p 23-27

25. C. Xu, M. Furukawa, Z. Horita, and T.G. Langdon, The Evolution of Homogeneity and Grain Refinement During Equal-Channel Angular Pressing: A Model for Grain Refinement in ECAP, Mater. Sci. Eng. A, 2005, 398, p 66-76 